\title{
Ensinar história a partir do esquecimento: um estudo de caso de educação patrimonial no Cemitério da Santa Casa, Porto Alegre/RS
}

\author{
Teaching history from forgetfulness: a case study of heritage \\ education at Santa Casa Cemetery, Porto Alegre/RS
}

\section{RESUMO}

Este artigo é baseado em uma experiência de estágio em Educação Patrimonial feito no Cemitério da Santa Casa da Misericórdia, em Porto Alegre/RS. Tomando a forma de um relato, o artigo propõe discutir as potencialidades de aprender e ensinar história a partir do espaço cemiterial. Enquanto representante de determinada espacialidade social, buscou-se trabalhar o cemitério como lugar de diferenças socioculturais, que constituem a história porto-alegrense. $O$ objetivo central foi abrir espaços de diversidade no patrimônio. Foram utilizadas para as visitas as faces do esquecimento que estão representadas na territorialidade do espaço, bem como as distintas manifestações estéticas e sua relação com as diferentes classes sociais ali presentes, propondo uma reflexão sobre o esquecimento e a permanência material, principalmente a partir do "Campo Santo". Esse é o lugar mais marginalizado do cemitério, o que também afasta sua memória, o que se tornou uma reflexão sobre a divisão espacial da instituição. Tecendo um ensino de história a partir das relações de poder, buscou-se um processo de sensibilização em relação ao próprio tempo e à morte, de modo a perceber o espaço cemiterial como constituinte simbólico de lembranças e esquecimentos existenciais.

Palavras-chave: Educação patrimonial - ensino de história - sensibilidades esquecimento - Santa Casa da Misericórdia/RS

\begin{abstract}
This article is based on an internship experience in Heritage Education (UFRGS), occurred at Santa Casa Cemetery, in Porto Alegre / RS. Taking the form of a report, the article proposes to discuss the potential of learning and teaching history from the cemetery space. As a representative of a particular social space, the cemetery was sought to be analyzed as a place of socio-cultural differences, which constitute Porto Alegre's history. The central objective, thus, was to open diversity gaps in heritage. In this way, the faces of oblivion that are represented in the space's territoriality, as well as the different aesthetic manifestations and its relation with the different social classes present there, were incorporated into the reflection.Thereby, a reflection on forgetfulness and material permanence was built, mainly through the "Campo Santo". This is the most marginalized place in the cemetery, what also marginalizes its memory: this particular aspect has been used to critique the institution's spatial division. Weaving a teaching of history from the power relations, a process of sensitization was sought in relation to time itself and death, in order to perceive the cemetery space as a symbolic constituent of existential memories and forgetfulness.
\end{abstract}

Keywords: Heritage education - history teaching - sensibilities - forgetfulness Santa Casa da Misericórdia/RS

* Mestrado pelo Programa de Pós-graduação em História da UFRGS. Bolsista CAPES (Coordenação de Aperfeiçoamento de Pessoal de Nível Superior). 
ste texto foi produzido no âmbito da disciplina de Educação Patrimonial da Faculdade de Educação da Universidade Federal do Rio Grande do Sul (UFRGS), ministrada pela professora Carmem Gil. Para a realização do estágio, obrigatório para o currículo de Licenciatura em História da UFRGS, cada aluno deveria escolher alguma instituição de memória, a fim de elucidar a potencialidade do ensino e aprendizado da história a partir do patrimônio. Para tanto, foi escolhido o Cemitério da Santa Casa, cujas iniciativas de educação patrimonial são realizadas há alguns anos pelo Centro Histórico-Cultural da Santa Casa, o que significa que é o próprio lugar que promove atividades educativas no espaço. ${ }^{1} \mathrm{O}$ estágio tomou a forma de uma visita guiada pelo espaço cemiterial, com a participação de alunos da educação básica de diversas escolas, públicas e privadas, das áreas próximas a Porto Alegre. Este relato objetiva explicitar como essa iniciativa foi construída em termos de ensino de história e educação patrimonial.

Como o cemitério é um lugar de expressão simbólica e material da finitude humana, e entendendo o tempo como constituinte da história, buscou-se promover uma sensibilização a respeito da morte como fim último da corporeidade (Derrida, 2015). O cemitério, enquanto lugar de educação patrimonial, pode proporcionar "uma experiência de contato direto" (Horta, 1999) a respeito das condições materiais que constituem o espaço mortuário e de luto. Segundo a visão do Instituto do Patrimônio Histórico e Artístico Nacional (IPHAN), para quem o patrimônio encarna certa temporalidade e reconhecimento social de determinada cultura, entende-se aqui "o cemitério como um lugar de aprendizado social", conforme sinalizado por Pedro Osório (2018, p. 81) em seu texto sobre pedagogia cemiterial. Enquanto lugar também de luto, o cemitério é um dos lugares que, de forma geral, proporciona aos sujeitos uma relação afetiva com os mortos, além de encarnar tanto continuidades quanto rupturas em relação ao tempo passado. É a partir do jogo entre memória e esquecimento, então, que é relembrada e esquecida a presença daqueles que, hoje, estão ausentes de corpo.

A partir do ensino de história baseado num patrimônio que contém continuidades e rupturas, é possivvel compreender que a relação entre presença e ausência é, também, um dos objetivos da própria escrita da história: fazer um rito de sepultamento, mas também trazer à tona certos passados esquecidos. Nesse sentido, uma história preocupada com as permanências e descontinuidades tem por objetivo reconstruir aquela imagem do passado que, antes, se fazia esquecida ou não elucidada. Nesse sentido, lembramos da célebre concepção de Michel de Certeau a respeito da escrita da história:

Com efeito, a prática encontra o passado sob a forma de um desvio relativo a modelos presentes. Na verdade, a função específica da escrita não é contrária, mas diferente e complementar com relação à função da prática. Ela pode ser particularizada sob dois aspectos. Por um lado, no sentido etnológico e quase religioso do termo, a escrita representa o papel de um rito de sepultamento; ela exorciza a morte introduzindo-a no discurso. Por outro lado, tem uma função simbolizadora; permite

1 O estágio ocorreu em 2018 e teve como supervisoras da instituição as historiadoras Juliana Mohr dos Santos e Gabriela Moreira, do Centro Histórico-Cultural da Santa Casa, cuja recepção e aprendizado eu gentilmente agradeço 
a uma sociedade situar-se, dando-lhe, na linguagem, um passado, e abrindo assim um espaço próprio para o presente: "marcar" um passado, é dar um lugar à morte, mas também redistribuir o espaço das possibilidades, determinar negativamente aquilo que está por fazer e, consequentemente, utilizar a narratividade, que enterra os mortos, como um meio de estabelecer um lugar para os vivos (Certeau, 1982, p. 106)

À história, logo, é proposta uma valoração tanto ontológica quanto moral, na medida em que explora diferentes sujeitos ao longo do tempo, bem como uma proposta de revisão ética com relação a um presente entendido como engajado (Sartre, 1970). A partir do espaço cemiterial, se propôs refletir sobre a escolha de quais passados trazer à tona para o presente, em ação construída a partir de um processo dialógico com os alunos. Enquanto historiador preocupado com uma "história vista de baixo", estudando sujeitos e categorias antes pormenorizados pela narrativa oficial, foi a partir dessas "brechas" existenciais, portanto, que a visita foi pensada. Dessa forma, as palavras de Marcelina das Graças de Almeida foram compartilhadas, em relação às práticas educativas no Cemitério do Bonfim, em Belo Horizonte, para quem as visitas cemiteriais possuem como objetivo "convidar o público participante a um processo de ressignificação dos espaços da cidade, estimulando a curiosidade e o sentimento de pertencimento" (Almeida, 2016, p. 223). Assim, buscou-se investigar primariamente o nivelamento temporal da morte em relação à diversidade do espaço cemiterial, ressaltando as diferentes formas pelas quais as dinâmicas de pertencimento, lembrança e permanência existem no lugar. Assim, foi proposta uma ressignificação do espaço cemiterial por meio das diferentes formas através das quais a memória e o esquecimento existem. Segundo esses saberes, produzidos e dispostos no patrimônio cultural, foi proposta uma consciência cidadã baseada na alteridade e na diversidade do patrimônio (Tolentino, 2016, p. 40).

As visitas, a partir de uma educação patrimonial tangente às subjetividades, ao mesmo tempo em que se mostraram preocupadas com a elucidação de sujeitos pormenorizados, foram efetuadas de modo a sensibilizar os alunos, trabalhando a espacialidade cemiterial segundo uma perspectiva ontológica em torno da existência e do esquecimento produzido por meio do patrimônio. Nesse sentido, o espaço cemiterial funciona como um corpus memorial diverso, performatizando desde representações estéticas refinadas de grandes figuras da política riograndense até as simples cruzes fincadas no chão de barro do Campo Santo.

\section{Abrindo brechas no patrimônio}

A historiadora francesa Sabina Loriga, ao analisar o movimento individual que compõe o espírito coletivo da história, afirma que "os últimos dois séculos viram nossos livros de história abundar em relatos sem sujeito: eles tratam de potências, de nações, de povos, de alianças, de grupos de interesse, mas bem raramente de seres humanos" (Loriga, 2011, p. 12-13), muito embora a autora desconsidere uma vasta produção voltada às subjetividades. Desde o início da história enquanto disciplina, seu coletivo singular (Die Geschichte) destinou-se a produzir 
uma "história única", cujo conceito serviu de base para o desenvolvimento da chamada História Universal: acima das histórias individuais, estaria "a História" (Koselleck, 2013, p. 119-184). Ao mesmo tempo, foi justamente esse caráter único e hegemônico da historiografia que pautou os ideais do Estado-nação moderno (Koselleck, 2013). Ademais, segundo Hannah Arendt (2014, p. 72), a história passou a ser o símbolo do progresso da modernidade: a história passou a ser não apenas narrada, mas, sobretudo, realizável. Essa conceituação do presente como lacuna incompleta (Arendt, 2014, p. 72), mas que é preenchida e orientada a partir da história, está na síntese da acepção moderna da história ocidental, da qual a historicidade faz abrir, pelo passado, um futuro mais esclarecido e iluminado.

Essas duas compreensões do conceito moderno de história - a) o "despertar" para o futuro e b) o aglutinamento das histórias individuais -, no entanto, estão presentes nas atuais discussões a respeito da escrita da história, na medida em que o tema da diversidade encontrase no centro das humanidades, principalmente como crítica a um nacionalismo hegemônico, ao mesmo passo em que a objetividade, o distanciamento e a técnica são questionados (Ávila; Nicolazzi; Turin, 2019). Segundo Loriga, muitas vezes a historiografia não acompanha a existência pelo fato de deixar os sujeitos anônimos, a partir de uma interpretação segundo a qual a história poderia ser comparada a uma escrita inerte, fria, insensivel e sem emocionalidade. A partir dessa problemática, as visitas, enquanto ações educativas da área de ensino de história, tiveram como objetivo explorar os sujeitos pormenorizados na espacialidade cemiterial, com atenção à diversidade memorial do patrimônio, com críticas à concepção de um patrimônio homogêneo e coeso. Dessa forma, foi estabelecido um contraste, tanto mnêmico quanto material, entre os bustos de mármore ali presentes e os muitos rostos que não possuíam sequer nome em suas cruzes, apenas um número de identificação.

Tensionando as relações entre memória e esquecimento produzidas pelo patrimônio cemiterial, buscou-se problematizar as diferentes manifestações de poder em relação à sua espacialidade, com atenção à forma pela qual as desigualdades memoriais são representadas nos jazigos. Dessa forma, buscou-se um engajamento crítico às questões sociais, bem como às interrelações estéticas e artísticas do espaço. Assim, num primeiro momento, com os estudantes à beira do portão central do cemitério, buscou-se dialogar sobre a construção daquele espaço sepulcral em relação à sua temporalidade, ressaltando as diferentes formas pelas quais os distintos corpos foram enterrados no local.

O cemitério da Santa Casa foi inaugurado em 1850, por ordem do Barão de Caxias (1803-1880), à época presidente da província do Rio Grande do Sul. De acordo com Mauro Dillmann (2008, p. 3), a Porto Alegre do início de 1840 "não comportava mais o aumento dos dois cemitérios que existiam na área urbana. Um estava localizado atrás da Igreja Matriz e do 
Palácio do Governo, e o outro nos fundos da Santa Casa de Misericórdia". ${ }^{2}$ Tanto Dillmann quanto Nascimento concordam em relação à compreensão de que o cemitério foi pensado a partir de uma preocupação sanitária, ${ }^{3}$ que estava de acordo com a introdução de um modelo liberal de urbanização e numeração. A partir de uma ideia de "circulação" (Nascimento, 2006, p. 295), foi estabelecida a criação de um cemitério além dos muros da cidade, de maneira que o lugar reservado aos mortos não pertencesse mais ao cotidiano civil, urbano e econômico da cidade, mas contando com um espaço específico de sepultamento. Nesse sentido, houve uma mudança urbanística em relação à construção do cemitério, representativa de uma ressignificação simbólica das atitudes para com os mortos. Assim, os demais lugares de sepultamento, muito embora nunca tenham sido impróprios para enterros enquanto durou a crença ad sanctos apud ecclesia (Nascimento, 2006, p. 305), eram situados no coração da cidade. À medida que os cemitérios passaram a ser lugares centrais de sepultamentos, os túmulos não seriam mais vistos na cotidianidade da igreja, tendo em vista uma mudança de atitude para com os mortos.

O que se avizinhava no horizonte da Porto Alegre de 1850, do qual a inauguração do cemitério da Azenha faz parte, era o afastamento dos sepultamentos em relação à urbe. Todavia, enquanto permanência ideológica, ele continuou como uma das formas pelas quais a religiosidade católica manifestava sua capilaridade, tendo em vista que foi dada à Santa Casa da Misericórdia a administração tanto do cemitério quanto do tráfego funerário - muito embora a instituição não fizesse parte da hierarquia católica do clero, haja vista que era uma instituição privada. ${ }^{4}$ Já de acordo com uma motivação sanitarista, presente na bibliografia, muito embora seja considerada por Nascimento mais como produto do que produtor da mudança, o local escolhido foi o morro da Azenha porque, dessa forma, o vento bateria na encosta do morro e afastaria a toxicidade dos miasmas do centro urbano. Assim, a construção do cemitério faz parte de um amplo processo de urbanização da sociedade riograndense surgido em 1850, que considerava o centro urbano o local por excelência de circulação e convivência moderna (Nascimento, 2006, p. 301). É nesse sentido que Pedro Meirelles (2016) observa, na medida em que a inauguração do cemitério extramuros da Azenha em 1850 foi o início de um processo

2 Conforme Mara do Nascimento (2004, p. 89) nos relata: "Em decorrência do trabalho delas [das irmandades religiosas], até o ano de 1850 a população porto-alegrense podia fazer uso de sete espaços sepulcrais dispostos no interior da urbe para realizar o enterro de seus mortos. Utilizados conforme critérios de diferenças sociais e étnicas ou de diferenciação hierárquica religiosa, estes espaços assim se distribuíam: os terrenos próximos à Santa Casa da Misericórdia, para certos doentes falecidos no hospital, alguns escravos e os protestantes chegados à Província a partir de 1824; o interior da capela de Nosso Senhor dos Passos, para os irmãos da Misericórdia e seus familiares; o adro da igreja Matriz, que se dividia em três: o cemitério, para os muitos pobres, as "covas de fábrica", para aqueles em que os familiares pagavam ao pároco pelo sepultamento, e as catacumbas das irmandades, exclusivas aos irmãos das Almas, do Rosário, do Santíssimo Sacramento, das Dores e da Conceição. O sétimo espaço poderia ser ainda o interior da própria Matriz, utilizado por alguns poucos privilegiados da sociedade local".

3 É necessário lembrar que, em 1850, os cientistas Pasteur e Koch ainda não haviam descoberto os microorganismos, o que estimulava a crença de que os miasmas, ar que exalava dos corpos em decomposição, eram o principal foco de doenças. A morte passou, então, a ser considerada não apenas uma questão ontológica, mas também sanitária, conforme nos mostram as declarações de Barão de Caxias, analisadas por Dillmann (2008).

4 Mara do Nascimento ressalta em sua tese que, desde sua fundação, as atividades cemiteriais obedeciam a certos critérios hierárquicos, como é o caso da diferença de valores para os carros funerários e para as classes de túmulos (ver Nascimento, 2006, p. 328-329). Desse modo, as taxas da sepultura (30\$000 a 1\$000) eram associadas às taxas da condução dos mortos (60\$000 a 1\$000). Conforme afirma a autora (2006, p. 320), "havia, pois, uma relação direta entre a posição social do indivíduo e a maneira pela qual ele seria apresentado à comunidade durante o percurso do féretro. Quando o novo cemitério é inaugurado, esta relação é mantida através da discriminação dos carros por "classes" 
mais amplo na então Província de Rio Grande de São Pedro, com importantes mudanças nas políticas cemiteriais e sanitárias. Segundo Mara do Nascimento (2006, p. 313), esse processo não deixa de fazer parte das políticas territoriais do Segundo Reinado, no intuito urbanístico de tornar as cidades unidades mínimas de regiões nacionalmente dependentes, que deveriam lutar juntas para o progresso da nação. Muito embora trate do contexto carioca, os estudos de Cláudia Rodrigues a respeito da especialidade cemiterial no mesmo período concluem que ocorreu um

gradativo processo de afastamento dos vivos em relação aos mortos, distanciamento que não foi só físico, mas, também, simbólico, na medida em que a morte e os mortos seriam progressivamente banidos da vida dos indivíduos cada vez mais preocupados com a saúde, com a vida (Rodrigues, 2002, p. 145).

Entre 1850 e 1866, a irmandade da Santa Casa da Misericórdia foi a detentora absoluta dos terrenos sepulcrais, vendendo em 1866 uma parte do terreno à irmandade de São Miguel e Almas. Dois anos depois, vendeu outra parte para a irmandade de Santa Bárbara. Muito embora ao longo da segunda metade do século XIX diversos cemitérios tenham sido inaugurados na área de Porto Alegre, entre 1850 e 1909, o Cemitério da Santa Casa foi o único localizado nas proximidades da urbe que, apesar de católico, aceitava o sepultamento da maioria dos indivíduos que faleciam na cidade, apesar de estar a cargo de uma irmandade particular de religião específica. Como as irmandades eram agentes de certa porosidade público-privada ao longo do Brasil Império, na medida em que a Santa Casa da Misericórdia era a responsável pelo cemitério, o espaço funcionava como cemitério público, inclusive sepultando em área contígua os mortos que não professassem da fé católica, em condições específicas (Nascimento, 2006, p. 299), enquanto os cemitérios de outros credos ainda não haviam sido criados. Nesse sentido, o cemitério possui grande importância para a sociedade porto-alegrense em relação às suas estruturas e suas formas de tratamento da morte, sendo o mais antigo da cidade. $O$ lugar, hoje, testemunha mais de cento e cinquenta anos de história, é um patrimônio histórico que contém muitas marcas de historicidade, bem como "heranças visíveis e invisíveis" (García Canclini, 1994, p. 94) da cidade.

O cemitério passou por diversas reformas e ampliações, desde sua inauguração em 1850. Foi também a partir do espaço cemiterial que ocorreu o fortalecimento da sepultura individual e nomeada, antes ausente nos sepultamentos intramuros ad sanctos, anônimos e coletivos. O sepultamento, dessa forma, figurou como "crescente individualização da vivência social da morte" (Nascimento, 2006, p. 316), estabelecendo um vínculo significativo de extensão familiar e individual. Ao mesmo passo em que o cemitério representou uma maior individualização do sepultamento, também representou anonimato para os menos afortunados.

Nesse sentido, ao longo da visita fez-se questão de ressaltar o Regulamento de 27 de novembro de 1850, lendo em voz alta todo o capítulo 1 da presente legislação, dos quais se ressaltam os termos "jazigos gerais e reservados", do artigo 2 , as três classes dos jazigos, bem como os sepultamentos para religiosos acatólicos e escravizados nas "imediações 
do Cemitério", ${ }^{5}$ em ambiente separado, dos artigos 4ㅇ e 5‥ A partir dessa perspectiva, foi explicitada a ideia de que o Campo Santo foi constituído como espaço de sepultamento dos menos favorecidos social e economicamente, sendo ainda hoje local de enterro de pobres e indigentes. Ainda no início da visita, com os alunos nos portões do cemitério, foi compartilhada a perspectiva de Mara do Nascimento, para quem o Campo Santo, pelo fato de ser localizado nos fundos do terreno (anteriormente, em área contígua), tratar-se do espaço mais marginal e simples do cemitério,

enquanto que as catacumbas e sepulturas dos contribuintes situavamse bem à frente, próximo ao portão em terreno mais enxuto e visível. A discrepância de valores para inumação num e noutro terreno denuncia claramente a relação que se estabeleceu entre hierarquias sociais e privilégio espacial, antes também presente entre as sepulturas ad sanctos e as do cemitério da Matriz (Nascimento, 2006, p. 298-299).

Nesse sentido, iniciada a caminhada da visita guiada, a problemática por mim desenvolvida foi determinar brechas na história oficial, a partir da materialidade do local, refletindo a respeito da dimensão humana que, muitas vezes, se escondia por entre os mausoléus e grandes jazigos que compõem o espaço cemiterial. O objetivo foi ensinar história a partir do esquecimento ao qual são submetidos os pertencentes às classes não dominantes, elucidando a forma pela qual tal desigualdade é distribuída no sepultamento. Assim, foi explorada a ideia de que as relações de poder não são expressas apenas a partir da vida, mas num controle de corpos do próprio morrer social, do nivelamento assimétrico que a finitude humana carrega para com a posteridade (Butler, 2018; Mbembe, 2017).

A visita foi composta por um caminhar entre os principais corredores do espaço, ressaltando as características estéticas de cada estátua de acordo com a história política riograndense. Entendendo as representações patrimoniais como produtos de determinados valores sociais, em certa altura da caminhada foram apresentados três jazigos próximos, com a solicitação de que os alunos notasseem suas semelhanças. Percebendo sempre o nome masculino antecedendo o nome da família nesses três jazigos - família Dr. João Leite, família Dr. Sinval Saldanha, família dr. Ismael Chaves Barcellos -, comecei a questionar as turmas, lendo as inscrições e aumentando o tom de voz na pronúncia do nome masculino: $O$ que tem nesses três túmulos? Tem algo de parecido nesses nomes? Ao que alguns respondiam: É o nome do homem. E eu: sim, pessoal, é sempre o nome do homem primeiro. Não é "família Leite: é família Dr. JOÂO Leite", como se a mulher precisasse sempre existir por intercâmbio do homem, como se o homem fosse o mais importante, como se o homem que precisasse ditar o nome da família. Os valores patriarcais são representados também na morte.

Ao longo da caminhada conjunta, foram vistos diversos túmulos de figuras políticas dos contextos riograndense e brasileiro, sobretudo líderes positivistas. Nesses jazigos, cuja maioria estava localizada nas alamedas centrais do cemitério, possuíam refinados adornos estéticos,

5 Para a transcrição completa dos artigos que compõem o Regulamento, consultar o anexo 4 da tese de Mara do Nascimento (2006, p. 332-340), cujo endereço eletrônico consta nas referências finais. 
foram exploradas suas diferentes representações estéticas, elucidando as distintas formas materiais com relação à morte, o que significa, os modos pelos quais os sentimentos familiares (alguns, estatais) eram dados aos seus mortos, bem como as relações morais presentes em algumas sepulturas. Em termos de representação material, foi esse o caso do jazigo da família Pedro Ellera, que possui a estátua da anja do Juízo Final que "olha" os transeuntes com a trombeta ainda abaixada e a cabeça pendendo para baixo, com um olhar de juízo. Também é o caso do grandioso jazigo de Júlio de Castilhos (1860-1903), cuja famosa inscrição "Os vivos são sempre e cada vez mais governados pelos mortos" denota a continuidade temporal positivista e a permanência de sua memória no solo cemiterial (ver Figura 1).

Figura 1. Túmulo de Júlio de Castilhos

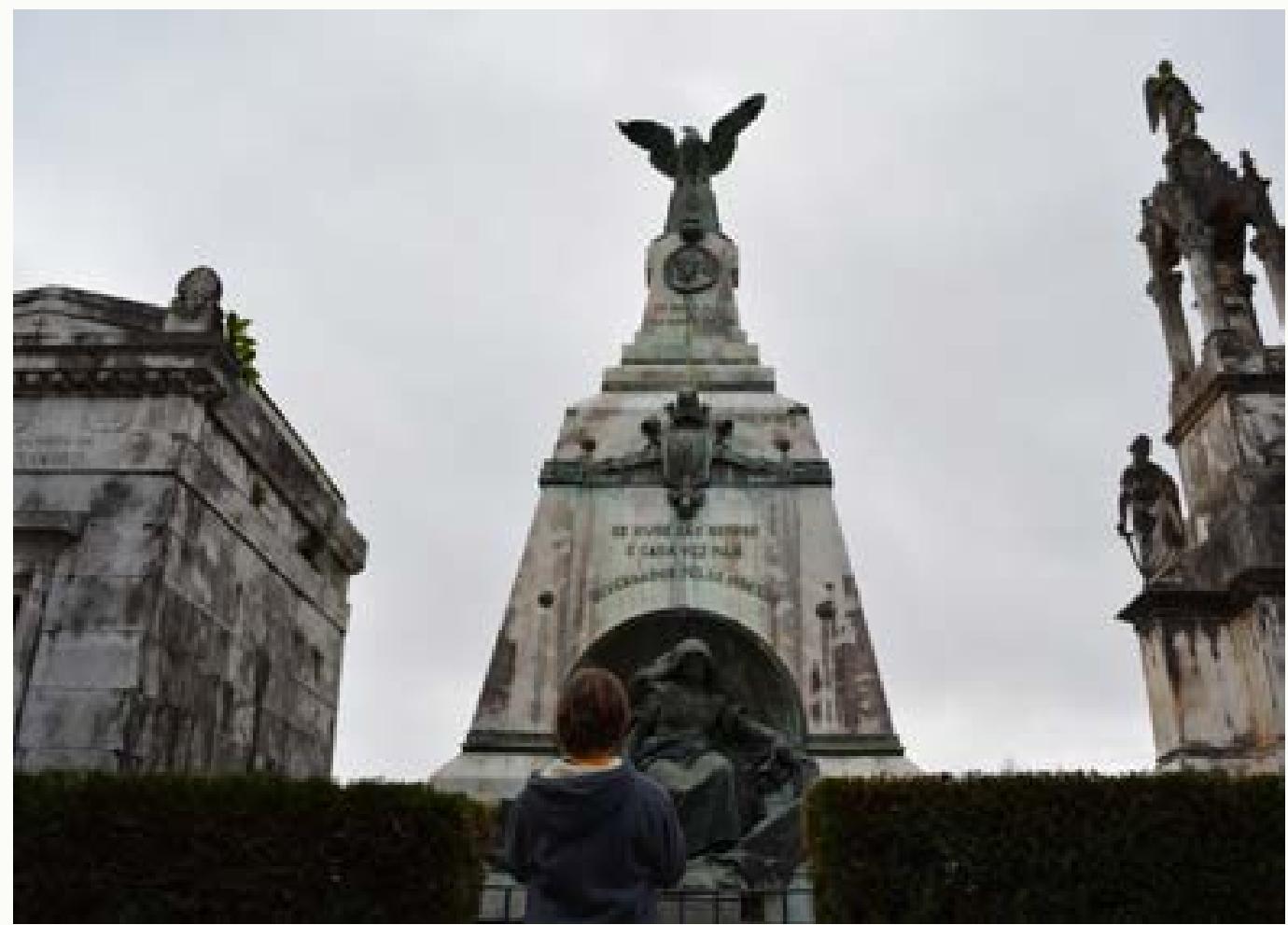

Fonte: Bruno Grigoletti Laitano/ Arquivo Pessoal

Outro caso é o do famoso túmulo de Pinheiro Machado (1851-1915), adornado por uma robusta escultura em ferro, que, com o peito aberto e indefeso perante o mundo, possui a República como guardiã. Ao lado desta está Clio, a musa poética que escreve seus feitos para a história. Como aforismo material, Clio relega a memória de Pinheiro Machado para as gerações futuras, sentenciando abaixo, com letras grandes: "O esquecimento é o nada/ a glória é a outra vida". Nesse sentido, foram interpretadas, com as turmas, as mensagens e memórias transmitidas por esses mortos pelas estátuas, com atenção às simbologias de cada uma.

Todavia, o que mais pautou a visita não foram as figuras femininas dos anjos de mármore ou as inscrições em latim, mas o espaço mais ao fundo do cemitério: o chamado Campo Santo, historicamente o lugar mais marginalizado. O local atualmente é constituído 
por um grande gramado com cruzes de ferro enumeradas em cima das sepulturas, no qual são enterradas majoritariamente pessoas que não têm condições de pagar por um túmulo. Nos dias atuais, em 2020, o cemitério doa dez sepulturas por dia para a prefeitura da cidade. A partir do sepultamento, os corpos permanecem ali por três anos. Após esse tempo, caso não haja contato ou a família não possua condições de transladar o corpo, a ossada é retirada do local para um crematório coletivo, com as cinzas jogadas no próprio Campo Santo. Contudo, esse não é o único local do cemitério sujeito à rotatividade. Quando os contratos de jazigos perpétuos expiram o prazo de 99 anos e não há renovação, são esvaziados e depositados num ossuário geral.

Narrativamente, o contraste estabelecido foi que, ao longo dos corredores do presente cemitério, foram vistas inúmeras formas mnêmicas de transmissão do passado: estátuas, mausoléus, cruzes em granito, às vezes mensagens de saudades do marido ou da família. Entretanto, no Campo Santo, na maioria das vezes não há qualquer representação artística ou estética, no máximo artefatos como finas fitas coloridas. Se, ao longo do espaço, há uma existência material da história e da memória, no Campo Santo reina tão somente o esquecimento, por si só imaterial, pois os enterrados lá não recebem sequer nome na cruz fincada no barro.

Já no final da caminhada, com o Campo Santo como visão final do trajeto, foi estabelecido um contraste a partir de um túmulo, cuja biografia havia sido contada quando passamos por ele: o de João Ferreira Porto (1782-1866), traficante de escravos, que inclusive tinha embarcação destinada ao tráfico negreiro em seu nome (Berute, 2011, p. 13-15). Perante ele há um grandioso e belo monumento: uma estátua de mármore com quatro figuras femininas, busto feito a partir de máscara mortuária, cinzel ${ }^{6}$ em mármore, etc. No momento foi enfatizado que, sobre o túmulo de Ferreira Porto, havia um grande monumento em mármore, cuidadosamente entalhado, com aforismos e requintes estéticos. Ressaltou-se que ele foi um traficante de escravos, tendo enriquecido por meio do comércio de seres humanos, deixando-os em condições miseráveis e insalubres. Se os traficantes de escravos possuíam poder econômico para construírem sepulturas requintadas, não seria demais afirmar que foi a própria venda da força produtiva dos escravos que possibilitou a construção de monumentos sepulcrais aos traficantes. Contudo, em que local estavam esses seres humanos? Antes de 1850, na área ao fundo do cemitério da Matriz, principalmente na área ao fundo do cemitério, espaço destinado aos mais pobres e menos favorecidos; após 1850, em área anexa ao cemitério da Santa Casa. Quanto a eles, não consta sequer memória, numa diáspora material e simbólica. Assim, foi indicado que a "história", assim como o patrimônio, por vezes testemunha somente os "grandes homens", como se tal atitude os tornasse "mais importantes", com "mais história". Dessa forma, sob o Campo Santo foi lida a célebre incitação à história por Marx e Engels: "Somos obrigados a lembrar que o primeiro pressuposto de toda a existência humana e, portanto, de toda a história, é que todos os homens devem estar em condições de viver para poder "fazer história" (Engels; Marx, 2005, p. 53). Enquanto espaço de memória, por intermédio de

6 Cinzel é uma ferramenta de corte que possui em uma extremidade uma lâmina aguçada. Utilizado com a batida de um martelo para abrir sulcos no material, é muito usado em trabalhos de escultura em pedra. 
um contato direto e sensível com a morte, demonstrou-se que o cemitério também obedece às relações de poder construídas ao longo da vida. A morte temporaliza exclusões.

Assim, a problemática central que norteou a visita guiada ao cemitério foram as produções de ausências memoriais em seu espaço. Segundo uma aproximação ontológica com a literatura de Svetlana Aleksiévitch (2016), o foco foi o "pequeno ser humano", elucidando as desigualdades sociais que se perpetuam inclusive após a morte no espaço. Nesse sentido, buscou-se estabelecer uma conexão sensível de alteridade com os alunos, problematizando a finitude humana a partir desse lugar de memória.

Apelo existencial junto a uma reflexão sobre a desigualdade da representação memorial no espaço cemiterial, foi distribuído um papel ao final da visita para cada aluno. Nesse, estava escrito "Hoje no cemitério eu aprendi que", de modo que cada um poderia completar de acordo com sua vontade. As respostas mais recebidas versaram sobre: "mesmo que todos sejam iguais perante a morte, a desigualdade também existe depois"; "precisamos viver cada dia como se fosse o último"; "hoje eu aprendi sobre a vida"; "os pobres não estão no cemitério"; "aqui estão ricos"; "a morte acontece com a vida"; "as mulheres tinham os nomes dos maridos"; "a história também acontece com os esquecidos".

Buscou-se, então, uma "sensibilização" por parte dos visitantes, com estímulos a pensar sobre as muitas histórias que são esquecidas no espaço cemiterial, bem como sobre os milhares de rostos que muitas vezes não viraram "história". Indaguei uma menina adolescente de um colégio da rede privada de ensino de Porto Alegre, que não quis escrever nada no papelzinho. Ela disse que se cobrava muito, que tinha ficado muito impactada com a visita. Respondi que tudo bem, que não precisava entregar, mas que, caso chegasse em casa e conseguisse elaborar aquele sentimento depois, podia enviar uma mensagem no Whatsapp, pois seria um prazer ler o que ela escreveu. Assim, passei meu número para ela. Eis que, por volta da meia-noite, a menina me chama. Transcrevo seu texto literalmente, com a devida autorização da autora, resguardando seu anonimato:

Creio que além de aprender, o dia de hoje foi um marco que me ensinou a pensar em mais do que apenas meu entorno. Cada túmulo não era apenas um túmulo, era uma pessoa, uma história e uma época passada com tantos acontecimentos que não consigo nem imaginar; Claro que eu já tinha esse conhecimento, mas o dia de hoje me fez parar para ler os epitáfios, ver as fotos e interpretar as obras de uma forma intensa, como nunca havia feito antes. Isso me fez ter ainda mais duvidas sobre a vida, a morte e o depois.

A história de Porto Alegre contada por mármore, estátuas e seus respectivos lugares no cemitério. Cada pessoa enterrada naquele solo com suas singularidades e preferências durante suas trajetórias me levam a pensar na vida das mesmas: "Quem eram?", "O que faziam?", "Quais eram seus sonhos?", "O que faziam aos domingos?", "Como pensavam que suas caminhadas acabariam?". O interessante foi pensar em pessoas que eu não tenho ligação alguma, pensar em épocas diferentes, com pessoas diferentes e em como o mundo muda e, da mesma forma, a sociedade continua igual, dando importância para os mesmos antigos costumes e valores fúteis 
Para uma pessoa sensivel como sou, a visita que fiz hoje ao cemitério Santa casa foi extremamente impactante. Com sensivel, quero dizer que tenho esse costume de misturar experiências com minhas próprias emoções e conviç̧ões. Penso que essa é a razão pela qual fiquei mais abalada que o normal.

Posso considerar a entrada a parte mais fácil da visita, após entrar, caminhando pela primeira parte do cemitério, passei a maior parte do tempo interpretando túmulos e criando questionamentos em minha cabeça, geralmente sobrea vida daspessoas alienterradas. Depoischegou a parte mais difícil. Sim, a anterior podia ser mórbida e melancólica, mas nada comparado àquela seção do cemitério. Chamam-a de Campo Santo, o lugar onde pessoas sem condições financeiras ou sem familiares são enterradas. Fiquei triste quando chegamos lá, minha visão sobre a história de Porto Alegre repentinamente virou outra: uma hierarquia econômica tão bem contrastada em um lugar em que todos acabam se tornarando iguais. Alguns na primeira parte do cemitério com lápides imensas, contando suas histórias, com suas fotos e obras artísticas para embelezar seus leitos, e outros apenas cobertos de terra em um terreno com um número de identificação. Fico abalada pela vida dessas pessoas não parecerem ter importância na época em que viveram, os nomes não serem revelados e suas histórias esquecidas, muitas vidas intrigantes escondidas pela barreira econômica que infelizmente tende e se perpetuar.

Finalizando o meu relato sobre essa experiência de hoje, a nova visão que descobri sobre Porto Alegre me chocou demais. Meu entendimento sobre a sociedade aumentou com essa visita e cada vez mais, meu sentimento de revolta com a desigualdade do país se reafirma.

Cada pessoa importa e cada pessoa merece respeito tanto na vida, quanto na morte.

Em um processo de identificação com a narrativa proposta, bem como com o próprio espaço cemiterial, a aluna percebeu a finitude à qual estamos todos submetidos. Com um ímpeto imaginativo, ela direcionou sua cognição não para decorar a data de nascimento e morte do governador Pinheiro Machado, ou quem eram os escultores de ascendência europeia que estavam presentes nas assinaturas dos mármores repaginados pelo minucioso trabalho do cinzel, mas para refletir sobre as pessoas cujos cadáveres estavam ausentes na permanência temporal do cemitério - muito embora a rotatividade dos jazigos não seja a priori exclusividade dos menos privilegiados. Logo, ela não pensou apenas na história, mas no que se encontra na raiz epistemológica da disciplina: o intercâmbio entre o lembrar e o esquecer.

\section{A título de epitáfio}

Foi justamente esse jogo, entre produção de presença e ausência, que pautou as visitas (Ricoeur, 2007). Em posicionamento contrário à divinização de grandes personagens históricos, o que poderia ser realizado de modo "natural" no cemitério, tendo em vista a grandiosidade dos bustos e a heroicidade dos grandes mausoléus, a preocupação foi evidenciar as brechas 
existentes no espaço, atentando às exclusões propagadas pelas estruturas sociais e pela própria história. Ao longo do artigo apresentei o processo das visitas, que atentou para a história do Cemitério da Santa Casa da Misericórdia e sua constituição espacial. Trata-se de uma proposta de um ensino de história tangente às ausências e desigualdades do patrimônio cemiterial. Afirmei que a história não foi dita de forma a sentenciar: "eis aqui um grande homem, olhem como seu túmulo é heroico, vejam sua magnificência, façam sua história tão grandiosa como a dele". Antes disso, a escolha foi empreender uma prática sensível de contato com outras alteridades, constituindo brechas no patrimônio cemiterial e estabelecendo uma narrativa a partir de suas ausências. Em oposição a uma ideia de patrimônio entendido como homogêneo, foi dito por mim: "olhem essas pessoas do Campo Santo. Perante elas, nenhum ornamento estético, nem sequer memórias. No entanto, elas foram tão importantes quanto qualquer outra personalidade que vimos ao longo da visita".

Assim, procurei demonstrar as potencialidades sensíveis de ensino de história a partir do patrimônio cemiterial enquanto espaço mobilizador da temporalidade e da finitude humana. Em oposição a um patrimônio erguido por uma heroicidade retumbante, foi feita menção à pequenez dos indivíduos e às desigualdades memoriais ali presentes. O reconhecimento em relação ao patrimônio foi construído a partir de suas diferenças e ausências. Nesse sentido, foi proposta uma identificação, a partir não apenas daqueles que foram lembrados e existem materialmente no cemitério, mas daqueles que foram, em parte, por ora, esquecidos.

\section{Referências Bibliográficas}

ALEKSIÉVITCH, Svetlana. A guerra não tem rosto de mulher. São Paulo: Cia. das Letras, 2016. $392 \mathrm{p}$.

ALMEIDA, Marcelina. A cidade e o cemitério: uma experiência em educação patrimonial. $R e-$ vista M. Estudos sobre a morte, os mortos e o morrer, Rio de Janeiro, v.1, n.1, p. 213-230, jan./ jun. 2016. http://doi.org/10.9789/2525-3050.2016.v1i1.213-230.

ARENDT, Hannah. Entre o passado e o futuro. São Paulo: Perspectiva, 2014. 309 p.

ÁVILA, Arthur; NICOLAZZI, Fernando; TURIN, Rodrigo (org.). A História (in)Disciplinada: teoria, ensino e difusão do conhecimento histórico. Vitória: Milfontes, 2019. 278 p.

BERUTE, Gabriel Santos. O tráfico negreiro no Rio Grande do Sul e as conjunturas do tráfico atlântico, c. 1790 - c.1830. In: ESCRAVIDÃO E LIBERDADE NO BRASIL MERIDIONAL, 5., Porto Alegre. Anais eletrônicos [...]. On-line, 2011. Disponível em: <http://www.escravidaoeliberdade. com.br/site/images/Textos5/berute\%20gabriel\%20santos.pdf>. Acesso em: 15 abr. 2020.

BUTLER, Judith. Quadros de guerra: quando a vida é passível de luto? 5a ed. Rio de Janeiro: Civilização Brasileira, 2018. 288 p.

CERTEAU, Michel de. A escrita da história. Rio de Janeiro: Forense Universitária, 1982. 414 p.

DERRIDA, Jacques. Adeus a Emmanuel Lévinas. São Paulo: Perspectiva, 2015. 144 p.

DILLMANN, Mauro. Simbolizando a devoção: irmandades, cemitério e enterramentos em Porto 
Alegre no século XIX. Fênix, Uberlândia, v. 5, n. 1, p. 1-15, jan./mar. 2008.

ENGELS, Friederich; MARX, Karl. A ideologia alemã. São Paulo: Martins Claret, 2005. 144 p.

GARCÍA CANCLINI, Néstor. O patrimônio cultural e a construção do imaginário social. Revista do IPHAN, Brasília, n. 23, p. 94-115, 1994.

HORTA, Maria L. P. et al. Guia básico de educação patrimonial. Brasília: Iphan, 1999. 68 p.

KOSELLECK, Reinhart. O conceito de história. Belo Horizonte: Autêntica, 2013. 230 p.

LORIGA, Sabina. O pequeno x: da biografia à história. Belo Horizonte: Autêntica, 2011. 231 p.

MBEMBE, Achille. Políticas da Inimizade. Lisboa: Antígona, 2017. 256 p.

MEIRELLES, Pedro von Mengden. Espetáculo de consternações - Os conflitos jurisdicionais na administração do cotidiano cemiterial na Piratini da segunda metade do século XIX. Aedos, Porto Alegre, v. 8, n. 18, p. 167-187, ago. 2016.

NASCIMENTO, Mara Regina do. Irmandades Religiosas na cidade: entre a ruptura e a continuidade na transferência cemiterial em Porto Alegre no século XIX. Estudos Ibero-Americanos, Porto Alegre, v. 30, n. 1, p. 85-103, jun. 2004. http://doi.org/10.15448/1980-864X.2004.1.23519.

NASCIMENTO, Mara Regina do. Irmandades leigas em Porto Alegre: Práticas Funerárias e experiência urbana - séculos XVIII-XIX. Tese (Doutorado em História) - Programa de Pós-graduação em História, Universidade Federal do Rio Grande do Sul, Porto Alegre, 2006. 362 p. Disponível em: <https://lume.ufrgs.br/handle/10183/8574>. Acesso em 15 mar. 2020.

OSÓRIO, Pedro Vianna. A cortina da memória dos mortos se abre à presença dos vivos: o cemitério e a aula de História. Aurora, Rio de Janeiro, ano 1, n. 2, p. 77-89, jun./dez. 2018.

RODRIGUES, Cláudia. Nas fronteiras do além: o processo de secularização da morte no Rio de Janeiro (séculos XVIII e XIX). 2002. Tese (Doutorado em História) - Programa de Pós-Graduação em História, Universidade Federal Fluminense, Niterói, 2002. 390 p.

SARTRE, Jean-Paul. ¿Que es la literatura? 4aㅡ ed. Buenos Aires: Editorial Losada: 1967. 320 p.

TOLENTINO, Átila. O que não é educação patrimonial: cinco falácias sobre seu conceito e sua prática. In: TOLENTINO, Átila; OLIVEIRA. Emanuel (org.). Educação patrimonial: políticas, relações de poder e ações afirmativas. João Pessoa: IPHAN-PB, 2016. Caderno Temático 5. 150 p. Disponível em: <http://portal.iphan.gov.br/uploads/publicacao/caderno_tematico_educacao_patrimonial_05.pdf>. Acesso em 15 mar. 2020.

Recebido em: 16 de abril de 2020

Aprovado em: 15 de outubro de 2020 